\title{
EFERVESCÊNCIA, DINAMOGENIA E A ONTOGÊNESE SOCIAL DO SAGRADO
}

Raquel Andrade Weiss

\section{Introdução}

Neste ano em que se comemora o centenário de publicação da mais controversa obra de Émile Durkheim, Les formes élémentaires de la vie réligieuse, proponho investigar um dos conceitos mais complexos e menos definidos de seu pensamento, e que ocupa uma posição estrutural na referida obra. Trata-se do relevante e obscuro conceito de sagrado. Embora muito já tenha sido escrito sobre o assunto, há ainda importantes elementos a serem explorados e lacunas à espera de serem preenchidas, e o presente artigo procura oferecer uma contribuição em relação a esse processo.

O ponto de partida da presente investigação foi precisamente o enfrentamento dessa questão por parte da literatura especializada, que permitiu que fossem identificadas as principais críticas e interpretações em relação a esse conceito da teoria durkheimiana. Embora nem toda essa literatura apareça o tempo todo de forma direta no texto, trata-se de uma interlocução constante que ajudou a destacar paradoxos e aporias, a elucidar ideias e a definir a parte desse terreno que ainda estava à espera de ser explorada. De modo geral, as duas principais referências para o mapeamento do "estado da arte" dessa discussão em torno do sagrado foram a biografia intelectual escrita por Steven Lukes (1973), na qual são sistematizadas e classificadas todas as críticas feitas até então pela literatura ao referido livro de Durkheim, e a obra-prima de William Pickering, Durkheim's sociology of religion, que se mantém ainda hoje como uma das principais referências, senão a principal, para o estudo desse aspecto da obra durkheimiana. Para considerações mais pontuais sobre esse debate em torno do sagrado, diversos outros trabalhos foram considerados, ainda que não sejam citados de forma exaustiva no corpo do texto. ${ }^{1}$

Mas, afinal, diante de toda essa gama de interpretações e análises, qual é a contribuição do presente artigo? O que proponho aqui é, primeiramente, realizar uma investigação sobre o sagrado, não tanto a partir de um esforço 
de reconstrução conceitual - embora esta seja uma etapa necessária do processo - mas, sobretudo, a partir de uma consideração do sagrado como um fenômeno real, e não apenas um conceito. Em outros termos, o que proponho é tentar compreender em que consiste o sagrado enquanto um fenômeno real e, em relação a isso, procuro identificar de que modo Durkheim oferece uma explicação para sua gênese ou, mais do que isso, de que modo podemos extrair de seus escritos uma teoria sobre a ontogênese do sagrado.

É evidente que a expressão não é propriamente aplicável a uma entidade que não possa ser considerada de fato como um "ser vivo", uma vez que a ontogênese consiste precisamente no processo de surgimento e desenvolvimento de um organismo, desde sua fecundação até o momento em que se torna um indivíduo desenvolvido por completo em sua composição orgânica. No entanto, acredito ser possível tomar a ideia de ontogênese como uma metáfora adequada de modo perfeito para nos referirmos ao processo que pretendo aqui descrever e explicar, isto é, não se trata apenas de identificar a gênese lógica ou temporal do sagrado, mas de compreender todos os passos de seu desenvolvimento, até tornar-se um elemento constitutivo e essencial da vida social.

Através deste artigo, nós nos propomos a entender o processo de formação do sagrado, mostrando que se trata de um fenômeno essencialmente social - social em sua gênese, social em suas funções e social no que toca à continuidade de sua existência. Desse modo, o que está em questão aqui é descobrir o que significa o social no contexto mais geral da teoria durkheimiana, o que nos levará a um conceito nuclear de Les formes élémentaires, qual seja, o conceito de efervescência. Além disso, procurar-se-á estabelecer conexões entre o sagrado e as dimensões da vida social que não coincidem plenamente com o fenômeno religioso: a dimensão inerente à moral.

\section{O sagrado e a religião}

Embora eu tenha acabado de afirmar que o sagrado é algo cuja extensão vai muito além da própria religião, não podemos ignorar o fato de que existe uma conexão intrínseca entre ambos, uma vez que o tratamento mais sistemático dado ao conceito de sagrado serve, sobretudo, para ajudar a elucidar sua concepção de religião. Desse modo, devemos dedicar alguma atenção a entender como o tema da religião figura em sua obra, desde seu início até seu desenvolvimento na fase mais madura. Ao fazê-lo, conseguiremos uma aproximação mais adequada com o tema que aqui nos interessa mais diretamente, e poderemos ter uma visão mais clara a respeito das complicações 
conceituais e dos enigmas explicativos que rondam ambos os conceitos, e que constituem precisamente o pano de fundo para as questões que proponho discutir mais adiante.

A primeira forma de registro mais sistemático da preocupação de Durkheim em abordar sociologicamente os fenômenos religiosos data do ano de 1894, quando ministrou seu primeiro curso sobre este assunto, cujo conteúdo foi parcialmente publicado em L'Année Sociologique, em um artigo intitulado "De la définition des phénomènes religieuses" (Durkheim 1899). Segundo o próprio autor, foi apenas nesse momento de sua carreira que se tornou mais claro em que poderia consistir uma abordagem essencialmente sociológica do fenômeno religioso.

Nessa ocasião, Durkheim tomou contato com os trabalhos de Robertson Smith e de outros autores de sua escola, em cujo âmbito a religião já era considerada como um fenômeno social, que teria como função manter a unidade do grupo e garantir suas ideias fundamentais (Lukes 1973:207). Na verdade, ao propor um estudo que se concentrava nos rituais, Smith abriu caminho para uma abordagem alternativa àquelas teorias psicológicas da religião, com as quais Durkheim debate em seu livro. Retrocedendo quase uma década, em 1886, encontramos em seu pensamento uma visão significativamente mais restrita sobre a religião, em que ela era concebida apenas enquanto uma instituição social que existia com a função de assegurar o equilíbrio da sociedade, agindo como uma forma de disciplina social. Em escritos de 1887, esta questão aparece ainda de maneira apenas tangencial, no contexto mais geral de discussões sobre a sociedade, e seu papel é definido como produto do sentimento que vincula o indivíduo ao ser social. Enfim, antes de 1895 não se encontra nenhuma formulação mais sistemática a este respeito.

Em "De la définition des phénomènes religieuses", considerado como um texto "pré-etnográfico", Durkheim apresenta uma definição essencialmente formal de religião, sustentada por uma série de hipóteses acerca da natureza deste fenômeno e de seu papel na sociedade, estabelecendo um conjunto de questões que deveriam ser investigadas pela sociologia da religião. Já em Les formes élémentaires, publicado em 1912, encontramos uma definição de religião diferente daquela de 1895, baseada em dados etnográficos de tribos australianas e calcada no conceito de sagrado. Mas qual a importância desses dados? Em sua introdução, Durkheim propôs que se poderia chegar com maior facilidade ao conhecimento dos elementos fundamentais da religião se o olhar fosse inicialmente dirigido para formas mais simples desse fenômeno, em que tais elementos deveriam aparecer de modo mais puro e evidente. Por isso sua escolha da religião totêmica, aquela em que esses elementos seriam mais facilmente apreensíveis. 
Antes disso, tanto a religião quanto o sagrado, e até mesmo Deus eram menções frequentes em seus textos sobre a moral, mas eles nunca eram suficientemente explicados. No texto que ficou conhecido como "o artigo sobre a Revolução" (Durkheim 1890), por exemplo, vemos figurar todas essas expressões, mas o conceito de sagrado não é explicado, nem há qualquer afirmação sobre sua relação com o de profano, assim como a ideia de religião é apenas um modo de se referir a algo que é objeto de fé, que é baseado em determinadas crenças e sustentado por diferentes ritos, mas não se vê o argumento, introduzido em Les formes, de que a religião pressupõe também o conceito de Igreja. Para que tenhamos uma ideia melhor a respeito da diferença entre esses registros, vamos recordá-los: "Uma religião é um sistema solidário de crenças e de práticas relativas às coisas sagradas, isto é, separadas, interditas, de crenças e práticas que unem em uma mesma comunidade moral, chamada Igreja, todos aqueles que a ela aderem" (Durkheim 1968:65).

Ora, em L'éducation morale, a ideia de religião não se parecia em nada com isso, sendo introduzida apenas como a forma mediante a qual as ideias morais sempre se apresentaram aos homens, de modo que entender o que é a moral em si mesma pressupunha descobrir o que havia de essencial na moral que se apresentava sob símbolos religiosos. Ou ainda, no texto sobre o caso Dreyfuss (Durkheim 1898), vemos Durkheim referir-se ao individualismo como uma religião, ao afirmar que "tal moral não é simplesmente uma disciplina higiênica ou uma sábia economia da existência; é uma religião na qual o homem é, ao mesmo tempo, seu fiel e seu Deus".

Em relação a isto, sugiro a interpretação de que não se trata de definições contraditórias de religião e de sagrado. Tudo nos leva a crer que possamos afirmar, ao menos a partir de 1895, a existência de uma definição "ampla" tanto de religião como de sagrado, e de uma definição "restrita", que é aquela apresentada em Les formes élémentaires, na qual a religião é tomada como um fenômeno sociológico composto de crenças e ritos e que reúne os fiéis em torno de uma Igreja, enquanto o sagrado é definido sempre em relação ao profano, e passa a ser o elemento central de constituição da religião. A definição ampla é menos rigorosa, e aceita sob essa designação uma pluralidade maior de situações; é o que permite se referir ao culto ao indivíduo como uma religião propriamente dita.

Mas ela não é necessariamente oposta à definição restrita. É importante que se tenha em mente esse duplo registro, para que se evite avaliar os argumentos pré-Formes élémentaires a partir de definições que só foram elaboradas depois. Mas tanto num caso como no outro, o que é mais essencial é que a religião e o sagrado são concebidos como fenômenos essencialmente sociais, que só na aparência nos vinculam a um mundo supramundano, isto é, dizem 
respeito a um mundo que aparece como transcendente para o indivíduo, mas é uma transcendência mundana, pois ambos são profundamente enraizados na realidade social. Se nos primeiros textos isto aparecia mais como uma hipótese ou como uma afirmação baseada em comparações metafóricas, no livro publicado em 1912 isto passa a ser explicado com muitos detalhes, inclusive com a utilização de dados fornecidos pelos relatos etnográficos.

Vamos nos concentrar agora nas considerações apresentadas em Les formes élémentaires, que são baseadas na afirmação de que a correta apreensão do fenômeno religioso depende da análise de suas partes mais elementares, quais sejam, as crenças e os ritos, definidos sumariamente no trecho a seguir:

Os fenômenos religiosos se dividem naturalmente em duas categorias fundamentais: as crenças e os ritos. Os primeiros são estados de opinião, consistem em representações; os segundos são modos de ação determinados. Entre estas duas classes de ação determinadas existe toda a diferença que separa o pensamento do movimento (Durkheim 1968:68).

De modo geral, as crenças são formas de representar e de classificar o mundo, que cristalizam as ideias que se tem a respeito das coisas, a respeito de sua ordem e de seu valor, enquanto o rito é um tipo particular de ação que se distingue das demais em virtude da natureza especial de seu objeto. Por enquanto, são as crenças que nos interessam particularmente, pois são elas que circunscrevem o domínio do sagrado e do profano. Ao afirmar que a crença é uma forma de classificação, já podemos perceber que, ao menos no livro em questão, o par conceitual sagrado/profano é um modo de classificação, um modo de divisão do mundo que existe em todo pensamento religioso, e é aqui que encontramos pela primeira vez no livro a ideia de sagrado:

Todas as crenças religiosas conhecidas, sejam elas simples ou complexas, apresentam uma mesma característica comum: elas supõem uma classificação das coisas que o homem representa para si mesmo, sejam elas reais ou ideais, em duas classes, em dois gêneros opostos, designados geralmente por dois termos distintos que são muito bem traduzidos pelas palavras profano e sagrado. Este é o traço distintivo do pensamento religioso, a divisão do mundo em dois domínios, um que compreende tudo o que é sagrado, e outro que compreende tudo o que é profano; as crenças, os mitos, os gnomos, as lendas são representações ou sistemas de representações que exprimem a natureza das coisas sagradas, as virtudes e os poderes que lhes são atribuídos, sua história, suas relações umas com as outras e com as coisas profanas (Durkheim 1968:68). 
A crença é um elemento básico do fenômeno religioso, e aquilo que há de mais fundamental nela é a divisão entre todas as coisas como sagradas ou profanas, isto é, a crença fundamental não é a existência de um deus, de vida eterna ou qualquer outra coisa, mas é uma representação a respeito do caráter dual do mundo, de modo que tudo aquilo que constitui objeto de adoração é sempre algo sagrado: o sagrado é anterior à ideia de Deus, o que amplia a própria noção de religião, englobando sistemas de crenças que não têm uma deidade, como, por exemplo, o budismo. É por isso que Pickering afirma que "para Durkheim, no coração de cada religião está o sagrado" (Pickering 2009:115). É o sagrado que define a religião, e não a religião que define o sagrado, ou seja, toda religião possui um sistema de crenças que ordena o mundo a partir de sua visão sobre o que é sagrado e o que é profano, mas a dimensão do sagrado como aquilo que é superior e inviolável não depende de uma religião.

O que é curioso em relação a esse conceito é que ele consiste no elemento mais importante do livro, mas não encontramos definições satisfatórias a seu respeito. Porém, é ele que constitui a essência das crenças e também dos ritos, e todas as explicações sobre o caráter extraordinário dos sentimentos coletivos são modos de exprimir o que é o sagrado. Assim, só teremos condições de ter uma visão mais correta das principais dimensões implicadas nessa ideia ao final da presente discussão, quando será possível perceber que o sagrado só é uma maneira de classificar o mundo porque ele corresponde, acima de tudo, a uma forma de percepção de uma realidade particular que se impõe ao homem como investida de um caráter excepcional, e é essa percepção que está na base de tal representação classificatória do mundo.

Antes de chegar lá, vamos reunir mais algumas informações sobre este conceito que, enquanto tal, aparece sempre em relação à sua antítese, o sagrado, pois, afinal, ainda segundo Pickering, "Durkheim não via o sagrado como um conceito isolado. Ele não subsiste sozinho e nem é unitário no mesmo sentido em que o é o suicídio, e por isso ele só adquire sentido em razão de seu oposto, o profano" (Pickering 2009:117). Se esta afirmação talvez não possa ser generalizada para os textos anteriores a Les formes élémentaires, ela é, sem dúvida, absolutamente válida para este contexto. É por isso que, quando se trata de definir tal conceito, nós o vemos sempre em relação ao profano, porque ele sempre aparece, em todas as tentativas de definição, como um dos polos do mundo representado pela consciência coletiva que aqui é expressa como "pensamento religioso":

Mas aquilo que é característico do fenômeno religioso é que ele sempre supõe uma divisão bipartida do universo conhecido e cognoscível em dois gêneros 
que compreendem tudo aquilo que existe, mas que se excluem radicalmente. As coisas sagradas são aquelas que os interditos protegem e isolam; as coisas profanas, aquelas às quais os interditos se aplicam e que devem se manter distantes das primeiras. As crenças religiosas são representações que exprimem a natureza das coisas sagradas e as relações que elas possuem entre si e entre as coisas profanas. E os ritos são as regras de conduta que prescrevem como os homens devem se comportar com as coisas sagradas (Durkheim 1968:68).

Ora, do sagrado continuamos a saber apenas que é o heterogêneo em relação ao profano, é aquilo que é protegido por interditos. Mas simplesmente não sabemos o porquê disso, por que o sagrado é o que ocupa um lugar à parte no mundo porque é aquilo que o profano não pode tocar. Ao contrário do que poderia parecer, o que define o sagrado não é que ele exprima o domínio do bem, enquanto o profano constitui o domínio do mal, o que talvez pudesse explicar o porquê desse seu caráter excepcional, mas sim que tanto o bem quanto o mal são parte daquilo que é representado como sagrado. É isso que somos levados a descobrir quando, ao concluir o Livro III, o autor introduz a discussão sobre os ritos piaculares - aqueles que têm como objetivo enfrentar uma calamidade, relembrá-la ou deplorá-la que revelam uma cisão interna no próprio sagrado, obrigando-nos a uma profunda reconsideração de qualquer ideia equivocada que possamos ter tido em relação ao profano enquanto oposição ao sagrado. Vejamos o que ele diz a respeito para depois discutirmos as consequências disso:

Propomos chamar de piaculares as cerimônias desse gênero. O termo piaculum tem, com efeito, não apenas a vantagem de sugerir a ideia de expiação, mas também de ter um significado mais abrangente. Toda infelicidade, tudo aquilo que é mau augúrio, tudo aquilo que inspira sentimentos de angústia,por conseguinte, é chamado piacular. Portanto, essa palavra parece bem apropriada para designar esses ritos que se celebram na inquietude ou na tristeza (É. Durkheim 1968:507).

Esses ritos são explicados a partir daquilo que Durkheim chama de ambiguidade do sagrado: ele é o santo e o maligno, o fasto e o nefasto, o puro e o impuro. O sagrado não é só o bem, é também o mal. O profano não é o mal, ele apenas não é sagrado. Sabemos que Durkheim afirma em relação à moral que ela goza de um caráter sagrado (Durkheim 2008, 2007 [1924]) e agora entendemos porque um interesse profano jamais pode se sobrepor a uma regra moral, pois, afinal, os bens morais simplesmente não podem ser comparados com os bens profanos, e é por isso que, por exemplo, não 
se pode atribuir um preço à vida humana, ou tentar decidir entre uma regra da moral e uma questão econômica, ou até mesmo estética.

Uma ação profana não ofende a moral, ela simplesmente lhe é indiferente - desde que ela não tente penetrar o domínio do sagrado. Discutir o valor estético de uma obra não é nem moralmente bom nem moralmente ruim; preferir bananas em vez de abacaxis é absolutamente indiferente do ponto de vista moral. Ultrajante seria querer comparar algo profano com algo sagrado, pois esses dois mundos devem permanecer incomunicáveis. Já o sagrado nefasto, impuro, é aquele que coincide com o mal, é o que provoca uma sanção negativa por parte da sociedade, é o que provoca horror, reprovação.

Do mesmo modo que o sagrado fasto e puro, ele também é algo que não se questiona, sobre o qual não se costuma falar, e que não pode ser comparado com as coisas profanas, porque representa tudo o que deve ser recusado, afastado de forma absoluta. Essa distinção introduzida no contexto dos ritos piaculares vem mostrar como a discussão sobre o sagrado contribui em mais um aspecto para a elucidação da ideia geral de moral, na medida em que sugere aquilo que está por trás da ideia e do sentimento do bem e do mal, oposição fundamental que caracteriza o domínio interno da moralidade. Além disso, também vemos que não seria correto dizer que aquilo que é social é bom e aquilo que é individual é mau, porque tanto o que é bom quanto o que é mau são igualmente definidos a partir de representações coletivas sobre o sagrado. A diferença reside, fundamentalmente, no tipo de sentimento coletivo que expressam, e que corresponde a distintas espécies de ritos.

Em um caso, são sentimentos positivos, de alegria, de celebração, pois se referem a tudo aquilo que é bom para a vida física e espiritual da coletividade, é tudo o que nutre e respeita seus ideais mais fundamentais. No outro caso, o sentimento coletivo experimenta sensações dolorosas que ameaçam seus valores mais arraigados, que põem em risco sua existência, provocam desespero e tristeza, comprometem sua própria sobrevivência, de seu corpo ou de sua identidade e, por isso mesmo, causam horror. Os rituais fúnebres dos Narrinyeri ou dos Watunga, narrados por Spencer e Gillen, são ritos piaculares que servem ao mesmo propósito de celebrações contemporâneas, como o Remembrance Day, no Reino Unido, ou as muito recentes cerimônias para lembrar o 11 de Setembro nos Estados Unidos, ou ainda os eventos para recordar a Shoah.

Todas estas são formas de afirmar o repúdio por acontecimentos que jamais deveriam ser repetidos, de ajudar os membros da coletividade a superar o sofrimento e, ao mesmo tempo, servem para reforçar os laços de solidariedade, fazendo com que se tenha a percepção efetiva de que o mal 
causado não diminui a força do ser coletivo. E é nesse sentido que também se referem ao domínio do sagrado. Mas o que de fato importa é que aqui temos uma ideia que nos aproxima mais daquilo que é o sagrado, que justificaria seu caráter de oposição ao profano: ele é sempre algo que diz respeito à vida coletiva ou, como resume Durkheim, "os dois polos da vida religiosa correspondem aos dois estados opostos pelos quais passa toda a vida social". E eles são o estado de elevada concentração e o de intensa dispersão da energia que emana da vida coletiva, isto é, "entre o sagrado fasto e o sagrado nefasto existe o mesmo contraste que há entre os estados de euforia e de disforia coletiva"(Durkheim 1968:580).

Enfim, se nada disso parece suficiente para definir o sagrado, ao menos temos uma melhor aproximação, pois já podemos notar que ele é "algo" que se refere à vida coletiva. A bem dizer, o sagrado é aquilo que parece circunscrever tudo o que constitui o domínio propriamente religioso e, por extensão, também caracteriza o que é moral, na medida em que contempla tanto o moralmente bom quanto o moralmente mau. Mas parece frustrante que esse conceito que define tanta coisa seja em si mesmo tão parcamente definido. Talvez aconteça com o sagrado o mesmo que se passa com as outras noções mais fundamentais da teoria durkheimiana, como as de sociedade e de moral: palavras e mais palavras, argumentos e mais argumentos, explicações e mais explicações versam sobre elas, mas não encontramos uma definição a seu respeito, nenhuma que as esgote, e isso provavelmente ocorre porque são essenciais.

É claro que isto não constitui problema algum, é apenas um fato que se destaca no âmbito de uma teoria tão insistentemente preocupada com as definições que, aliás, estabelece a definição como a primeira dentre as regras de seu método (Durkheim 1998). Mas vamos então "seguir com a maré", deixando de lado essa preocupação com definições, para ir na direção da descrição da realidade que estaria por trás de tudo aquilo que subjaz a essa ideia de sagrado, ou melhor, que dá origem a essas representações coletivas que concebem o mundo como se ele fosse partido em dois.

\section{Efervescência e dinamogenia: um sagrado mundano}

Em outras ocasiões (Weiss 2011, 2012) apontei, ainda que brevemente, a estreita relação que existe entre o conceito de ideal e o de sagrado, já que uma das maneiras possíveis de definir o ideal é enquanto uma "ideia sagrada", isto é, uma representação dotada de uma intensa carga emotiva que não apenas fala ao pensamento, mas inspira a ação. Na realidade, mais do que 
uma afinidade conceitual, estes dois termos apresentam uma semelhança real, pois possuem uma origem comum.

Vamos, então, mergulhar mais fundo nesse processo, tentando dissecar e entender tudo aquilo que está implicado na ideia de sagrado, que tem nas situações de "efervescência" o seu momento constitutivo.

\section{O elementar universal da vida religiosa}

Após a publicação de Les formes élémentaires, Durkheim engajou-se seriamente nas atividades de divulgação da recente obra, não tanto para torná-la conhecida - àquela altura o autor já gozava de amplo prestígio nos meios intelectuais, o que garantira a rápida divulgação de seu novo livro mas especialmente para aclarar seu sentido. Afinal, parecia que lhe causava alguma frustração o fato de seu argumento mais essencial ter escapado até de seus melhores e mais dedicados leitores, como, por exemplo, Gustave Belot, o primeiro a redigir uma resenha sobre o livro (Belot 1913).

Da parte dos "homens de fé" Durkheim já não gozava de grande apreço em parte em virtude de seu comprometimento com a instituição de uma educação moral laica e de seu antimonarquismo. Como se não bastasse querer ensinar uma moral sem Deus, ainda inventou de publicar um livro que não apenas tinha o grave inconveniente de procurar explicar sociologicamente a religião, afirmando ser ela um fenômeno social em essência, como ainda cometeu a grosseria de comparar as religiões altamente intelectualizadas e espiritualizadas, como o protestantismo e o catolicismo, às religiões tribais. ${ }^{2}$

Todavia, até mesmo aos libres penseurs o seu mais recente trabalho parece ter causado incômodo, em virtude talvez de sua insistência em querer mostrar aquilo que havia de verdadeiro em todas as religiões, por afirmar que a religião não é uma mera "alucinação coletiva", ou seja, num contexto de um laicismo extremamente combativo, sua explicação para o fenômeno religioso parecia ser demasiado condescendente para com as religiões, mesmo que ele fosse muitíssimo crítico em relação às Igrejas, em especial à Igreja Católica, chegando a afirmar que, "do ponto de vista sociológico, a Igreja é um monstro" (Durkheim 1905:369).

Tendo desagradado aos mais radicais de ambos os lados, em vez de simplesmente combater de frente cada uma das críticas que lhe foram dirigidas, ele concentrou os esforços em mostrar que seus leitores não haviam compreendido aquilo que, na realidade, era o mais importante de tudo o que ele escrevera. Assim, talvez uma das melhores maneiras de se 
compreender Les formes élémentaires seja tomar essas ponderações posteriores como chaves de leituras. Aliás, no primeiro debate público a respeito de seu livro, no qual teve ocasião de expô-lo, ele formulou de maneira bastante interessante a natureza de sua inquietação e aponta qual é, então, esse elemento mais fundamental, sugerindo, inclusive, o porquê de não ter sido bem compreendido:

Não poderia pensar em resumir aqui o livro que publiquei recentemente. Mas gostaria de colocar em relevo a razão de ser fundamental da religião, que permite preparar melhor os espíritos a aceitar a explicação que eu propus a seu respeito. Essa razão de ser se vincula a uma das características mais essenciais da religião, mas que não é imediatamente perceptível, precisamente porque é essencial. Ela não é formulada logo no início do livro. Ela aparece apenas progressivamente, na medida em que o estudo avança, e é especialmente na conclusão que ela ganha destaque. Essa característica é aquilo a que poderíamos chamar de virtude dinamogênica de toda espécie de religião (Durkheim 1913b:17).

Desta forma, a principal característica da religião é sua virtude "dinamogênica". É curioso, no entanto, que esta expressão não aparece em momento algum em Les Formes, de modo que é preciso saber a que isso se refere para que tenhamos condições de saber aquilo que há de mais fundamental na explicação de Durkheim sobre a religião e também sobre o sagrado. A ideia de dinamogenia fazia parte do vocabulário intelectual da França de fins do século XIX e começo do XX, tendo sido utilizada pela primeira vez (Miller 2005), ao que tudo indica, pelo fisiologista Charles-Édouard Brown-Séquard (1882) em seu livro Recherches expérimentales et cliniques sur l'inhibition et la dynamogénie, publicado no ano de 1882, tendo sido popularizada por Charles Ferré (Ferré 1885, 1887).

Seu significado inicial se refere a uma ativação intensa de um órgão em virtude de uma excitação provocada por causas de qualquer natureza, e é este sentido que o termo recebe, por exemplo, no dicionário Houaiss da língua portuguesa. Já em francês, encontramos nos dicionários apenas a forma adjetivada, "dynamogénique", definida como "aquilo que acrescenta energia, que estimula, que aumenta o tônus vital". Mesmo tendo sido uma expressão cunhada num contexto da fisiologia, ela logo entrou no vocabulário da filosofia e até mesmo no das artes, tornando-se muitíssimo utilizada durante as primeiras duas décadas do século $\mathrm{XX}$, o que talvez explique porque Durkheim tenha recorrido a ela para resumir processos descritos em seu livro, mas que eram designados por um termo que não estava tão "na moda": o de "efervescência". 
Ora, se a principal razão de ser da religião é sua virtude "dinamogênica", isto quer dizer que o que há de mais essencial nela é esse aumento de energia que ela provoca nos indivíduos, que é mais importante, inclusive, que sua função como instrumento de ordenação e explicação do mundo, como um sistema de representações. Tudo isso parece secundário diante daquilo que há de mais essencial na "experiência religiosa", isto é, na religião tal como ela é experimentada pelo crente, que sente como se ele fizesse parte de algo grandioso, sente-se fortalecido, nutrido, elevado pela experiência de sua fé, o que levou Durkheim a afirmar que, para os fiéis, "a verdadeira função da religião não é nos fazer pensar, nem enriquecer nossa consciência", mas, é, sobretudo, "fazer-nos agir, ajudar-nos a viver"(1968:595).

Por isso mesmo "o fiel que comungou com seu deus não é apenas um homem que conhece verdades novas, que o não crente ignora; ele é um homem que pode mais" (1968). Aliás, nessa mesma discussão na Société Française de Philosophie, na qual ele mencionou a ideia de virtude dinamogênica da religião, ele ainda argumentou que essa característica não apenas corresponde a algo real, como ainda garantiu que a religião tivesse se mantido como um elemento universal de todos os povos no decorrer da história:

Mas esse afluxo, em si mesmo, não possui nada de imaginário; ele é real. Esse aumento da vitalidade se traduz nos fatos pelas ações que inspira. O homem possui uma confiança, um ardor, um entusiasmo que ele não experimenta em tempos ordinários. As provações da existência encontram nele mais forças de resistência; ele é capaz de grandes coisas, o que prova por sua conduta. É essa influência dinamogênica da religião que explica sua perenidade (Durkheim 1913b:17).

Vemos, portanto, que a explicação daquilo que há de mais essencial na religião depende de se compreender como é possível essa atividade dinamogênica. Para o fiel, essa energia é vista como uma participação da divindade, fruto do contato com seu Deus ou seus deuses, que são representados, acima de tudo, como uma grande potência. Porém, "os deuses não são senão os ideais coletivos personificados", "a divindade não é outra coisa senão a sociedade transfigurada"(Durkheim 1913:69), ou seja, eles não são em si mesmos entidades reais, são apenas a forma simbólica de algo real que, conforme já está indicado aqui, é a própria sociedade, a própria vida coletiva, o que o leva rapidamente a afirmá-la como a verdadeira instância originária desse influxo energético que aumenta a vitalidade do indivíduo:

Não podemos senão perceber que é a sociedade a única coisa que pode exercer essa ação dinamogênica que caracteriza as religiões. Que ela seja capaz 
de produzir esse efeito é o que me esforcei para mostrar. Eu explicitei como ela estimula a atividade, aumenta a vitalidade, eleva o indivíduo acima de si mesmo, o sustenta e o reconforta (Durkheim 1913:68).

Com isso, temos já todos os elementos importantes para retornarmos a Les formes élémentaires, para identificar como ele tentou mostrar que a vida coletiva é realmente capaz de produzir esse efeito, agora que já sabemos ser este o elemento mais importante da vida religiosa. Um dos momentos mais interessantes em que vemos uma formulação a esse respeito é o da conclusão, quando Durkheim parece atribuir um novo sentido aos numerosos ritos que ele descrevera no decorrer de todo o livro. Ali, vemos ainda com maior nitidez que fundamental na vida social, no que se refere à dinamogenia, é a própria ação em comum. Isto ocorre porque a sociedade faz sentir sua influência quando se manifesta em ato, na ação, isto é, quando os indivíduos estão reunidos e agem conjuntamente. É esse agir em comum que cria a percepção desse ser comum, e é essa ação que viabiliza a criação dos sentimentos coletivos e mesmo das ideias coletivas, isto é, das próprias crenças, dos próprios ideais:

Do fato que representemos um objeto como digno de ser amado e buscado, não se segue que nos sintamos mais fortes; é preciso que desse próprio objeto emanem energias superiores àquelas de que dispomos e, mais do que isso, que exista algum meio de fazê-las penetrar em nós, misturando-se com nossa vida interior. Ora, para tanto, não é suficiente que pensemos, é preciso que nos coloquemos em sua esfera de ação, que estejamos numa posição que permita sentir essa influência; resumindo, é preciso que ajamos e que repitamos os atos que são necessários todas as vezes que desejarmos renovar seus efeitos. [...] Isso é porque a sociedade não pode fazer sentir sua influência a não ser que ela exista em ato, e ela não existe em ato a não ser quando os indivíduos se reúnem e agem em comum. É pela ação comum que ela toma consciência de si e se afirma; ela é, antes de tudo, uma cooperação ativa. Até mesmo as ideias e os sentimentos coletivos só são possíveis graças aos movimentos exteriores que os simbolizam, tal como já estabelecemos (Durkheim 1968:395-398).

Com isso, começamos a nos aproximar mais do que pode ser entendido como sagrado e dos processos que estão em sua origem. Um pouco mais acima, vimos que as crenças são definidas como formas de representar e classificar o mundo, sendo a principal dessas classificações a sua divisão entre o sagrado e o profano. No trecho que acabei de citar, Durkheim afirma que "até mesmo as ideias e os sentimentos coletivos" só são possíveis em 
virtude desses "movimentos exteriores", isto é, dessa ação comum, o que nos leva a ver nessa ação coletiva que engendra a dinamogenia o elemento que constitui o próprio sagrado, que é exatamente aquilo que permite afirmar que o sagrado é algo real.

No trecho seguinte veremos o autor se referir ao sagrado como uma característica das representações coletivas, que se diferencia das representações individuais por constituir não um estado mental que representa coisas distintas, mas por corresponder a formas de vida diversas, o que nos oferece uma interessante ideia sobre o sagrado como algo que caracteriza certos tipos de representação, adjetivando-as, mas que é em si mesmo um sentimento produzido por uma determinada realidade sui generis:

Tanto uma quanto a outra formam em nossa consciência dois círculos de estados mentais, distintos e separados, como as duas formas de vida às quais correspondem. Por conseguinte, temos a impressão de estar em relação com duas espécies de realidades, distintas entre si, como se houvesse uma nítida linha demarcatória que separa uma da outra: de um lado, está o mundo das coisas profanas e, de outro, aquele das coisas sagradas (Durkheim 1968:301).

Assim, temos mais um elemento para entender como o sagrado é criado. Ele não é uma invenção. É um modo de representação de algo real, que se apresenta aos indivíduos de forma muito particular. O sagrado é a forma com que os indivíduos representam essas forças que resultam da própria interação, é um modo de pensar e se relacionar com a vida coletiva que, tão logo é representada, figura como elemento estranho porque, conquanto cada indivíduo seja parte dessa coletividade, esta se torna, pelo fato básico da interação, uma realidade qualitativamente diferente: é a interação que cria uma "força psíquica", e é essa força que se percebe como o sagrado. O momento seguinte é o processo mediante o qual esse atributo se estende a coisas e pessoas particulares, que passam a ser um sagrado mais concreto, mais palpável, mais evidente: assim são os grandes heróis, os deuses, os grandes líderes, os santos, os sacerdotes, e outros. Mas desta forma também são os símbolos, como o totem, o Santo Graal, o bastão de um feiticeiro na tribo, a Bíblia, o Corão, a Torá, e assim também são, e é isso o que nos importa, as ideias.

No contexto da religião, as ideias que são investidas desse caráter sagrado são aquelas chamadas de crenças. Num sistema religioso há muitas ideias, mas só algumas delas possuem um caráter inviolável, que o fiel não ousa questionar. É o que Durkheim chama de "interdito da crítica", que é mais um tipo de interdito dentre os muitos que podem proteger aquilo que é sagrado. Sempre que se adere a algo que não se aceita questionar, que está 
acima de qualquer outra coisa, pode-se dizer que se está em face de algo que é sagrado. É precisamente nesse sentido que o "individualismo moral" ao qual se refere Durkheim constitui uma crença, sendo investido de um caráter sagrado, assim como todos os "dogmas" a ele associados.

Ora, isto acontece porque o individualismo é um ideal moral no sentido mais estrito do termo, e um ideal moral é um tipo de crença. Ou melhor, a crença é um ideal moral, que recebe este nome quando faz parte de um sistema que constitui uma religião. Durkheim às vezes parece tomar estes dois termos de forma intercambiável, mas em outros momentos vemos com mais nitidez essa separação, e é importante que se perceba essa diferença. O ideal do individualismo assume a forma de uma crença porque ele é um ideal moral, e toda crença é um ideal social, e não o contrário. Isto porque, como também já vimos, é Deus a forma hipostasiada da coletividade, e não a coletividade é um Deus - e inverter os termos da equação é inverter toda a lógica da teoria durkheimiana. Na citação a seguir, vemos como o sagrado é explicitamente constitutivo da noção de ideal e de crença:

Assim como consagra homens, a sociedade também consagra as coisas, e notadamente as ideias. Quando uma crença é unanimemente partilhada por um povo, pelas razões que expusemos acima, ela é proibida de ser tocada, isto é, não pode ser contestada. Ora, o interdito da crítica é um interdito como todos os outros e prova que estamos em face de algo sagrado. Até mesmo nos dias de hoje, por maior que seja a liberdade que concedamos uns aos outros, um homem que negue totalmente o progresso, que ridicularize o ideal humano ao qual as sociedades modernas são vinculadas estará fazendo algo que tem o mesmo efeito de um sacrilégio. Existe ao menos um princípio que os povos que mais prezam o livre exame tendem a colocar acima de qualquer discussão e a considerar como intangível, isto é, que consideram como sagrado: é o próprio princípio do livre exame (Durkheim 1968:305).

A primeira frase deste inserto traz uma afirmação muito interessante: é a sociedade que consagra as coisas, inclusive as ideias, isto é, ela as transforma em algo mais do que a coisa mesma. Mais do que isso, trata-se de um processo coletivo de consagração, que metamorfoseia simples objetos, simples ideias, em algo absolutamente excepcional. Vamos ver agora em que consiste esse processo que faz com que essa "força" seja real e, para apreendê-lo em sua forma mais elementar, nada melhor, segundo Durkheim, do que recorrer aos ritos praticados nas religiões totêmicas.

Faremos isto a partir de uma descrição de um desses processos de efervescência consubstanciado em rituais da tribo dos Warramunga, que 
constitui um dos exemplos mais interessantes trazidos por Durkheim. Não posso me furtar aqui de trazer ao texto a belíssima sugestão de Miller, que aponta para uma incrível semelhança entre esses processos descritos em Les formes élémentaires e as cenas do balé de Stravinsky, Le sacré du printemps, que este autor caracteriza como

a estética total de uma música-dança-drama sagrada, com cenas que lembram aquelas conjuradas nas Formas elementares, e performada na mesma época em que Durkheim estava enfatizando a preocupação de seu livro com a ação dinamogênica que está no núcleo de toda religião (Miller 2005:27).

Esta menção aparece para trazer à cena o ésprit de l'époque que colocava em destaque a ideia de dinamogenia, inclusive no meio das artes; mas o que eu sugiro é que aqui tenhamos em mente a coreografia, a narrativa, o sentimento provocado pelos movimentos dos bailarinos e pela música de Stravinsky, que em seu conjunto fazem o expectador viver a experiência desse momento de sagração. Com essa imagem diante dos olhos, vejamos agora uma das cenas rituais descritas por Durkheim, que ele tomou como exemplo dos rituais que estão na base da produção do sentimento de sagrado. O que veremos a seguir se refere às tribos australianas que praticam o totemismo que, segundo Durkheim, teriam suas vidas divididas em dois momentos bem distintos: a vida regular e ordinária, submetida às regras normais e voltadas para a produção econômica, quando a população permanece dispersa, organizada em pequenos grupos; e a vida que tem lugar nos momentos de concentração e condensação, quando ocorre uma cerimônia religiosa ou quando acontece aquilo que na etnografia da época se chamava de corrobbori, que se distingue das cerimônias estritamente religiosas por ser mais abrangente, incluindo as mulheres e os não iniciados. É o corrobbori que é descrito a seguir. A citação é longa, mas este é o único recurso que temos para trazer ao texto esta imagem que não pode ser reconstruída senão como descrição:

Quando acontece um corrobbori tudo muda. Como as faculdades emotivas e passionais do primitivo são imperfeitamente submetidas ao controle de sua razão e de sua vontade, ele perde facilmente o controle sobre si mesmo. [...] Uma vez os indivíduos estejam reunidos, resulta dessa aproximação uma espécie de eletricidade que os transporta rapidamente a um extraordinário nível de exaltação. Cada sentimento expresso repercute, sem qualquer resistência, em todas as consciências que são amplamente abertas às impressões exteriores: cada uma delas ecoa as demais consciências reciprocamente. O impulso inicial vai se ampliando na medida em que repercute, como uma avalanche que au- 
menta na medida em que avança. E como paixões tão intensas e tão liberadas de qualquer controle não podem deixar de extravazar, o que se vê, por todos os lados, são gestos violentos, urros, ruídos ensurdecedores, que intensificam ainda mais o estado que manifestam. Certamente, dado que um sentimento coletivo não pode se exprimir coletivamente a não ser que seja observada alguma ordem que permite harmonizar os movimentos, esses gestos e esses gritos tendem a se ritmar e a se regularizar; a partir disso, surgem os cantos e as danças. [...] As paixões desencadeadas são tão impetuosas que não se deixam conter por nada. As pessoas se sentem fora das condições ordinárias da vida e têm tanta consciência disso que se experimenta quase uma necessidade de estar acima da moral ordinária. Os sexos se juntam contrariamente às regras que regulamentam as trocas sexuais. Os homens trocam suas mulheres. Às vezes, até mesmo uniões incestuosas, que em tempos normais são consideradas abomináveis e são severamente condenadas, são contraídas ostensivamente e impunemente. Se acrescentarmos a isso o fato de que tais cerimônias geralmente ocorrem à noite, em meios às trevas que a luz da fogueira penetra aqui e ali, poderemos facilmente representar o efeito produzido por essas cenas sobre os espíritos de todos os participantes. Essas cenas determinam uma superexcitação tão violenta da vida física e mental que não pode ser suportada por muito tempo: o ator que tem o papel principal acaba por cair exausto no chão (Durkheim 1968:310).

Se as cenas descritas por Spencer e Gillen ${ }^{3}$ não são rituais de sacrifício, como vemos em Le sacré du printemps, e nem possuem o mesmo apelo estético, o que está presente na coreografia idealizada por Vaslav Nijinsky é um movimento similar, ritmado, histérico, com ares de mistério e que, ao mesmo tempo, refere-se a algo absolutamente natural, pois são as próprias forças da natureza que se revestem, em virtude desse movimento, de uma aura de mistério. A cena que reproduzi logo acima menciona gritos, batuques, orgias, mas há outras no mesmo livro que descrevem rituais de destruição e sacrifício, assim como em Le sacré. Todavia, o que importa de fato é que em ambos os casos, seja nas orgias, seja nos sacrifícios, existe um sentimento de exaltação, de transe, algo que faz com que corpos e mentes se sintam como partes de algo que os domina.

Talvez seja bastante sintomático que a primeira apresentação pública da dança tenha ocorrido um ano após a publicação de Les formes élémentaires não por haver qualquer tipo de influência de um lado ou de outro - mas porque são expressões diversas de um tema que parecia aflorar naquele meio intelectual. Stravinsky diz ter sido inspirado a escrever essa inaudita composição a partir de um sonho que tivera com um ritual pagão, o que o teria levado a sentir efeitos sonoros indefiníveis. Durkheim não foi inspirado por qualquer sonho, mas 
não se pode negar o impacto de sua "descoberta" dos rituais totêmicos sobre a formulação de sua concepção mais acabada sobre a religião, sobre a origem do sagrado, que explicaria tanto a religião quanto a própria representação de Deus e, mais do que isso, fundamentaria a própria moral.

A reação do público francês na noite de estreia desse ballet revolucionário em sua música e em sua dança é bastante conhecida e fez história. Que um virtuose da dança tenha feito algo tão estranhamente "bizarro" era algo ultrajante, assim como as notas de Stravinsky, que ofenderam a sensibilidade musical tão bem formada do público tradicional, salvo daqueles que representavam a verdadeira avant-garde da época e souberam perceber a genialidade do que haviam acabado de presenciar. Evidentemente, a comparação com o conteúdo de Les formes élémentaires não tem qualquer pretensão de estabelecer um paralelo fiel, muito menos uma relação de equivalência. Essa referência aparece aqui quase na função de uma metáfora, para elucidar com imagens que nos são familiares um processo ritual que está muito distante de nós, e que Stravinsky soube eternizar no seio da modernidade, tornando-o parte de nossas representações coletivas, por assim dizer. Já que chegamos até aqui, peço licença para um último passo adiante nesse paralelo, que se refere ao momento de "recepção" de ambas as obras.

No caso de Les formes élémentaires, não se pode dizer que a reação enfurecida tenha se dado de forma tão intensa e quase unânime como em Le sacré du printemps, mas as críticas não foram poucas e nem amenas. E não apenas por parte dos representantes eclesiásticos e dos intelectuais que professavam alguma fé, mas até mesmo daqueles que se declaravam ateus ou agnósticos, como pontuei mais acima. Dentre os muitos pontos de controvérsia, sugiro que nos detenhamos em um deles em particular, que se refere mais diretamente ao problema que aqui nos toca. Muito sucintamente, a grande questão é a seguinte: como é possível que se pretenda explicar a religião e mais, o próprio sagrado, a partir da descrição de um processo que parece essencialmente carnal, pagão, que contraria todos os valores morais? Como pode o fundamento da moral - o sentimento de sagrado ser buscado em um evento que parece tão imoral? Como algo tão avassaladoramente natural e terreno pode ser o momento de criação de algo tão sublime e transcendente como o sentimento do sagrado?

Pois é aqui mesmo que Durkheim acreditava residir o trunfo de sua teoria. Vamos primeiro levar em consideração que esse processo que ele descreve aqui se refere a um contexto muito particular, isto é, nem todo processo coletivo que produz efervescência se configura da mesma maneira, pois admitir o contrário disto seria decretar que o sagrado não pode ser produzido, por exemplo, nas sociedades modernas, o que, do ponto de vista 
da teoria durkheimiana, teria sérias implicações morais. Mas esses rituais totêmicos têm a grande vantagem de apresentar os elementos centrais desse processo de uma forma explícita, exagerada mesmo, o que facilitaria em muito a apreensão de seus aspectos mais "elementares", isto é, mais básicos, mais fundamentais.

E aquilo que há de mais elementar nisso tudo, no que se refere à sua importância para a constituição do sagrado, é o fato básico de que esse estado de efervescência, provocado pela densa aproximação entre as consciências que se influenciam mutuamente, provoca naqueles que tomam parte do ritual um estado mental de um tipo completamente diferente daquele que o indivíduo experimenta em sua vida ordinária. "Concebe-se facilmente que, quando começa esse estado de exaltação, o homem já não se conhece mais", afirma o autor, ou seja, existe uma reação de estranhamento em relação a seu próprio ser.

Mas o que o homem percebe no momento em que ele experimenta esse estranhamento? Uma sensação de ser "dominado, arrebatado por uma espécie de poder exterior, que o faz pensar e agir de modo diferente do que o faria em tempos normais" (Durkheim 1968:313). E ele não é o único a vivenciar essa sensação diferente, ele não é o único a usar máscaras, todos aqueles que estão à sua volta experimentam a mesma coisa, e externam essa vivência por meio de gritos, choros, pulos, danças e, olhando a seu redor, ele realmente tem a nítida sensação de habitar um mundo diferente. A intensidade e a repetição dessa experiência acabam por fixar a percepção quanto à existência desses dois mundos distintos, heterogêneos. Um é monótono, mecânico, repetitivo e, nele, sua vida se resume a realizar tarefas cotidianas necessárias à sobrevivência material. O outro é extraordinário, leva-o a experimentar forças poderosas, promove um estado de grande frenesi, faz com que ele realize coisas de que jamais se imaginou capaz. É essa dualidade que é refletida na separação do mundo entre o profano e o sagrado. Nesse momento, o sagrado coincide com aquilo que é extraordinário, extracotidiano, poderoso, transfigurador e, por que não, inexplicável.

\section{Considerações finais}

O que vimos aqui, portanto, é como os momentos de efervescência configuram-se como a instância originária do sagrado que, por sua vez, está na base de todo fenômeno religioso e também moral. Certamente, a intensidade e o modo com que esse processo ocorre nas religiões mais complexas são muito diferentes, mas essas diferenças não fazem com que deixem de ser, essencialmente, a mesma coisa. No mundo moderno, as consciências estão 
naturalmente menos distanciadas no cotidiano, de modo que os momentos de aproximação mais estreita dificilmente produzirão um efeito que goze da mesma intensidade.

Talvez este seja precisamente um dos maiores desafios não apenas para as teorias sociais contemporâneas, mas para a própria sociedade como um todo. Se assumirmos haver alguma razoabilidade nos argumentos de Durkheim, o sagrado não é um fenômeno essencial apenas para a manutenção das próprias religiões, mas sim uma condição sine qua non para a existência da própria vida social, na medida em que é precisamente quando temos um sagrado em comum que podemos partilhar certos valores. E o que é uma sociedade para Durkheim senão uma comunidade moral, isto é, uma comunidade de indivíduos que não apenas vivem num mesmo território, mas que também têm em comum alguns ideais?

A questão de encontrar algum valor que possa ser considerado sagrado pelos membros tão diversos de uma sociedade é em si mesmo um objetivo sujeito a questionamentos mas, mesmo que se reconheça isto como algo desejável, estabelecer qual seria esse valor parece ser um desafio bastante complicado. Sabemos que o autor acreditava ter encontrado uma saída, e foi por isso mesmo que defendeu o respeito à pessoa humana como valor irredutível das sociedades modernas (Durkheim 1890, 1898b, 2007). Ainda assim, embora aceitemos que a vida em sociedade só é possível quando se comunga de uma fé em comum ao menos de um único ideal, e assumindo que esse ideal possa ser o respeito à pessoa humana, há uma questão - teórica e prática - cuja resolução parece ser ainda mais desafiadora. Trata-se de saber como o sagrado - não o sagrado particular das muitas religiões pode continuar a existir nas sociedades contemporâneas, ou seja, como é possível engendrar momentos de efervescência suficientemente abrangentes que viabilizem o surgimento de novos ideais compartilhados ou, ao menos, que tornem possível a renovação da fé comum em alguns valores bastante gerais. Ou, em outros termos, o desafio, deste ponto de vista, é como a vida social pode continuar a ser percebida enquanto tal, enquanto vida coletiva, ativa e com propriedades dinamogênicas.

Recebido em 04 de julho de 2012

Aprovado em 06 de maio de 2013

Raquel Andrade Weiss é professora adjunta do Departamento de Sociologia da Universidade Federal do Rio Grande do Sul. E-mail:<weiss.raquel@gmail. com> 


\section{Notas}

${ }^{1}$ Outros trabalhos relevantes e que serviram como referência, em maior ou menor grau, são os seguintes: Godlove 1989; Prades 1987; Seger 1957; Jones 2005; Poulat \& E. Durkheim 1970; Fabris 1981; Westley 1983; Filloux 1990; Pickering 1990; Alexander 1990; Isambert 1992; Allen et al. 1998.

${ }^{2}$ Para uma análise abrangente da reação dos católicos e protestantes à obra durkheimiana, não se pode deixar de ler o recente artigo publicado por William Pickering (2008), que preencheu uma importante lacuna no campo das pesquisas que visam reconstruir o meio intelectual de Durkheim.

${ }^{3}$ Francis James Gillen e Walter Baldwin Spencer foram os dois importantes etnógrafos especializados nos estudos das tribos australianas, cujos relatos serviram como referência para a análise que Durkheim realizou do totemismo, já que ele jamais "foi a campo".

\section{Referências bibliográficas}

ALEXANDER, Jeffrey. 1990. "The sacred and profane information machine: discourse about the computer as ideology". Archives de Sciences Sociales des Religions, 35(69):161-171.

ALLEN, Nicholas J. et al. 1998. On Durkheim's elementary forms of religious life. London: Routledge.

BELOT, Gustave. 1913. "Une nouvelle théorie de la religion". Revue Philosophique, 75:329-379.

BROWN-SÉQUARD, Charles É. 1882. Recherches expérimentales et cliniques sur l'inhibition et la dynamogénie: applications des connaissances fournies par ces recherches aus phénomènes principaux de l'hypnotisme et du transfert. Paris: Masson.

DURKHEIM, Émile. 2008. A educação moral. Petrópolis: Vozes. - 1898a.L'Année Sociologique. . 1898b. "L'individualisme et les intel- lectuels". Revue Bleue, 10:7-13.

- 1913. "Le problème religieux et la dualité de la nature humaine". Bulletin de la Sociéte Française de Philosophie, 13:63-100.

- 1968. Les formes elementaires de la vie religieuse. Paris: Presses Universitaires de France.

. 1890. "Les principes de 1789 et la sociologie". Revue Internationale de l'Enseignement, 9:450-456.

- 1998. As regras do método sociológico. São Paulo: Martins Fontes.

. 2007. "O ensino da moral na escola primária". Novos Estudos Cebrap, 78:61-75.

-1924. Sociologie et philosophie. Paris: Fékix Alcan. . 1905. "Sur la séparation des églises et de l'État [contribuição à discussão]". Libres Entretiens de L'Union pour la Vérité, 1:369-371, 496-500. 
FABRIS, Matteo. 1981. Morale e religione in Emile Durkheim. Bari: Edizioni Levante.

FERRÉ, Charle. 1885. "Sensation et mouvement". Revue Philosophique, 20:337-368.

FILLOUX, Jean-Claude. 1990. "Personne et sacré chez Durkheim". Archives des Sciences Sociales des Religions, 69(1):41-53.

GODLOVE, TerryF. 1989. Religion, interpretation, and diversity of belief: the framework model from Kant to Durkheim to Davidson. Cambridge: Cambridge University Press.

ISAMBERT, FrançoisA. 1992. "Review: Une religion de l'homme?: sur trois interprétations de la religion dans la pensée de Durkheim". Revue Française de Sociologie, 33(3):443-462.

JONES, Robert A. 2005. The secret of the totem: religion and society from McLennan to Freud. New York: Columbia University Press.

LUKES, Steven 1973. Émile Durkheim, his life and work: a historical and critical study. London: Allen Lane.

MERLLIÉ, Dominique 2010. "Cinq comptes rendus de Durkheim à découvrir". Durkheimian Studies, 16(1):3-11.

MILLER, WilliamW. 2005. "Dynamogénique and élementaire".Durkheim Studies, 11:18-32.

PICKERING, WilliamS.F. 2009. Durkheim's sociology of religion - themes and theories. Cambridge: James Clarke \& Co. - 1990. "The eternality of the sacred: Durkheim Error?".Archives de Sciences Sociales des Religions, 69:91-108. . 2008. "The response of catholic and protestant thinkers to the work of Émile Durkheim - with special reference to Les Formes Elementaires". Durkheim Studies, 14:59-93.

POULAT, Émile\& DURKHEIM, Émile. 1970. "La conception sociale de la religion: retour à un texte peu connu de Durkheim". Archives de Sociologie des Religions, 15(30):87-90.

PRADES, José A. 1987. Persistance et métamorphose du sacré: actualiser Durkheim et repenser la modernité. Paris: Presses Universitaires de France. SEGER, Imogen. 1957. Durkheim and his critics on the sociology of religion. New York: Columbia University/ Bureau of Applied Social Research.

WEISS, Raquel. 2012. "From ideas to ideals: effervescence as the key to understanding morality". Durkheim Studies, 18:81-97.

-2011. Émile Durkheim e a fundamentação social da moralidade. Tese de Doutorado, São Paulo, Universidade de São Paulo.

WESTLEY, Frances. 1983. The complex forms of the religious life: a durkheimian view of new religious movements. Chico, Calif.: Scholars Press. 
Resumo

O tema central do presente artigo é a ideia de sagrado apresentada por Émile Durkheim em diversos momentos de sua obra, mas que ocupa um papel central no livro As formas elementares da vida religiosa. Trata-se de uma ideia de difícil definição, mas que é fundamental para explicar tanto a religião quanto a moral, e que é compreendida pelo autor como um dos fenômenos mais importantes da vida social. O que se propõe aqui é explicar de que modo Durkheim concebe o surgimento e o desenvolvimento desse fenômeno. Defendo a tese de que tal explicação demanda que se compreenda o que é a efervescência e, por conseguinte, a dinamogenia. Ao apreender o pleno significado desses conceitos, torna-se possível um maior entendimento sobre o que é realmente o sagrado e sobre o significado de este ser um fenômeno social por excelência.

Palavras-chave Durkheim, Efervescência, Sagrado, Moral, As formas elementares da vida religiosa.

\section{Abstract}

The main theme of the present paper is the idea of "sacred" as presented by Émile Durkheim on several occasions, most particularly as the central theme of his book, The Elementary Forms of Religious Life. It is an idea that is quite hard to define, but fundamental in explaining not only religion but also morality, understood by the author as one of the most crucial elements of social life. What is intended here is an explanation of how Durkheim conceived of the genesis and the development of this phenomenon, sustaining the thesis that this explanation requires understanding what is effervescence and, therefore, dynamogenics. In understanding the full meaning of these concepts, we can better comprehend what is the sacred and its meaning as a social phenomenon.

Key words Durkheim, Effervescence, Sacred, Morality, The elementary forms of religious life. 